\title{
Uma paisagem abstrata: Fargo, o erro e a imagem-mental
}

\section{João Martins Ladeira}

Universidade Federal do Paraná, Programa de Pós-Graduação em Comunicação, Curitiba, PR, Brasil https://orcid.org/0000-0002-7381-6380

\section{Resumo}

Analisa-se Fargo, filme de Joel e Ehan Coen, na expectativa de interpretá-lo a partir do conceito de Deleuze de imagem-mental. A despeito de seu formato aparentemente convencional de comédia de crime, a obra é aqui entendida como exemplo de um trabalho localizado na fronteira do cinema clássico, sem nunca romper com seus limites. Compreende-se o filme como indício de um deslocamento na imagem-ação, recorrendo menos ao synsigno/binômio, recurso intrínseco à segundidade. Em Fargo, torna-se dispensável a contraposição entre os eventos e os atos que os guiariam de uma situação a outra. Ao se subordinar os gestos a uma ideia, faz-se com que tal filme opere segundo uma terceiridade, introduzindo pensamento na imagem e conferindo centralidade a um conceito que se define pelo erro, do qual a obra se torna sua ilustração. Fargo explora essa mecânica, em gestos fadados a conduzirem à destruição de tudo que compõe a trama.

\section{Palavras-chave}

Imagem-mental; Irmãos Coen; Deleuze

\begin{abstract}
"A história que se segue (...) [e]voca a paisagem abstrata de nossa infância (...). Tem por alvo ser ao mesmo tempo familiar e exótica, e finge ser verdadeira" (COEN, 1997).
\end{abstract}

\section{Introdução}

Um marido planeja o sequestro da esposa como meio de extorquir dinheiro de seu sogro. Para isso, contrata dois bandidos. Quando os capangas que conduzem a vítima no porta-malas do carro são parados por um vigilante rodoviário graças ao descuido que os faz se esquecerem de fixar as placas do automóvel, o encontro termina na morte do patrulheiro e de outras pessoas que passavam pela rodovia. A policial designada inicia as investigações do homicídio sem desconfiar do sequestro. Suspeitas esparsas a levam até a concessionária em 
que o marido trabalha, sem supor a culpa desse homem. Sem que, contudo, a detetive desvende o plano em curso, a prisão do último culpado depende de evidências coletadas de modo trivial. Chega-se ao esconderijo dos bandidos, e, na conclusão, há apenas um dos sequestradores para prender: desavenças banais entre os parceiros haviam resultado na morte de um dos criminosos, e essa última prisão conecta todos os eventos.

Há muitas maneiras de contar a história de Fargo: Uma Comédia de Erros (Fargo, 1996, de Joel e Ethan Coen) ${ }^{1}$, e a análise que aqui se segue se atém a seu caráter errático, no qual o filme se revela uma coleção de eventos guiada menos pelo desdobramento de certas ações, e mais por uma ideia latente à obra do começo ao fim. Fargo funciona como uma equação. A ingenuidade do mandante, Jerry Lundegaard (William H. Macy) ou as escolhas patéticas dos dois sequestradores, Carl Showalter (Steve Buscemi) e Gaear Grimsrud (Peter Stormare), submetem-se a um conceito que conduz todo o trajeto. Ao contrário de um filme que, guiado pela imagem-ação (DELEUZE, 1983, 1985), apresentasse um duelo no qual as habilidades da policial, Marge Gunderson (Frances McDormand), recuperassem a vítima, Jean Lundegaard (Kristin Rudrüd), acompanhamos uma história na qual a heroína possui bem pouca influência na conclusão do caso e a vítima encontra apenas sua destruição.

Comédias de crime consistem num gênero guiado pela inversão da pretensa potência sobrenatural tanto de criminosos quando de bandidos, retratando-os estúpidos e inofensivos a ponto de produzirem o riso (LEITCH, 2002). Fargo ultrapassa essa tendência. Como um indício da modernidade dos Coen, associa-se a um cinema em que as ações se submetem a conceitos que as organizam. Trata-se do limite para o cinema clássico, a fronteira da imagemmental, numa arte livre da relação com o synsigno e o englobante, o binômio e o duelo, esses que localizam pulsões abstratas num meio concreto, onde a luta com outros homens ou com o meio é realisticamente conduzida. Em contraponto aos gestos que levam a situação de um estado a outro, os conceitos se externam sobre gestos de bem pouca importância.

0 cinema clássico se definiu pelo tratamento dado à contraposição tanto com o ambiente quanto com os demais personagens, concentrando-se na montagem orgânica, instrumento capaz de guiar a narrativa de um ponto a outro, numa estratégia para conectar

\footnotetext{
${ }^{1}$ Sexto filme de Joel e Ethan Coen, e um de seus principais sucessos, Fargo foi concebido após o fracasso de público de Na Roda da Fortuna (The Hudsucker Proxy, 1994). Recebe diversas premiações - dois Oscars e o prêmio de melhor diretor em Cannes e se transforma num dos poucos consensos da crítica até então sobre os Coen. Cineastas classificados como integrantes de um cinema de baixo orçamento e intensa qualidade estética, a carreira dos irmãos se inicia nas franjas da estrutura de produção dos anos 1980, quando se afirmam como autores com total controle sobre seus produtos. Sua obra é analisada pela ênfase ao caráter farsesco, tanto irônico quanto desdenhoso em relação a seus personagens e tramas, assim como pela atenção à violência: marcas intensas, repetidas a ponto de conceder a seus enredos um ar de estranheza, distância e irrealidade (LEWIS, 2011).
} 
as imagens e desdobrá-las segundo uma lógica que envolve sempre o conflito entre duas partes. Mas, para a imagem-mental, surge uma terceiridade no lugar do confronto típico da segundidade ${ }^{2}$. No caso dos Coen, essa ideia remete ao erro, enganos que conduzem os planos de um criminoso à destruição e que impedem a detetive de solucionar o crime. Os cineastas surgem menos como artistas pós-modernos pautados pela retomada sistemática de signos e mais como donos de uma obra guiada por um objeto de pensamento a atuar fora desse mesmo pensamento.

Certa leitura de Fargo frisou a distância entre sua pretensão de realidade e seu caráter estilizado. Essa suposta história "baseada em fatos reais" possuía uma fotografia de estilo documental, abordando os personagens com movimentos de câmera simples, estáticos. Seus cenários eram escolhidos privilegiando lanchonetes e escritórios banais. Os atores se expressavam em sotaques fiéis a Minnesota. 0 filme era permeado de cenas sem qualquer objetivo aparente: a conversa de Marge com Norn (John Carroll Lynch) sobre minhocas e o encontro da policial com Mike Yamagita (Steve Park). Essa técnica se contrapunha à trama inusitada, abordagem semelhante à de Stanley Kubrick em Doutor Fantástico (Dr. Strangelove no original, de 1964), cuja austeridade documental do relato inicial se choca com a irrealidade dos eventos posteriores (ADAMS, 2015; CIMENT; NIOGRET, 2006).

Outras interpretações viram em Fargo uma tensão entre certa defesa ontológica do cotidiano, simbolizada por Marge, e a irracionalidade da violência, ilustrada pelos sequestradores. 0 filme refletia sobre o caráter patológico dos relacionamentos latentes por baixo do verniz de cordialidade da América provinciana. Logo, a cena mais importante seria aquela em que a policial conduz Gaear enquanto lhe passa um sermão de professora primária sobre seu crime. Pois, embora Marge tenha se mostrado hábil na solução da trama, encadeando certo grupo de eventos, a personagem se depara com sua própria incapacidade em aceitar tamanha violência. Marge refletiria o temor existencial da ausência de sentido no mundo, numa defesa recorrente da rotina através de um postura que concede um centro moral a um universo absurdo (PALMER, 2004).

A interpretação aqui proposta difere dessas duas leituras, talvez as abordagens mais sistemáticas sobre o filme. Nisso, a cena mais importante se torna menos a do instante final, e

\footnotetext{
2 Primeiridade, segundidade e terceiridade são conceitos de Peirce apropriados de modo muito particular por Deleuze. Em sua obra, dizem respeito a três tipos de imagens, a imagem-afecção, a imagem-ação e a imagem mental. Respectivamente, descrevem um plano de pura qualidade localizado fora de coordenadas tempo-espaço; a inserção de determinado afeto num ambiente localizado, permitindo o desdobramento de ações que usualmente envolvem o confronto; a expressão de uma pura ideia, como um exercício intelectual que torna visível um pensamento.
} 
mais o interrogatório entre Jerry e Marge, em que parece absolutamente impossível esquivarse do erro frente à incapacidade da detetive em apreender aquilo que levaria à solução do crime. Embora Palmer tenha indicado o quanto os personagens parecem sempre imersos em sua incapacidade de apreender seus atos para além de limites muito estreitos, essa explicação remete ainda às motivações psicológicas. Contudo, interessa menos uma dimensão pessoal e mais a ilustração de uma ideia através de imagens de equívocos intermináveis, seja com os ambientes nos quais circulam, seja com os outros indivíduos com que se relacionam.

\section{Legados da narrativa policial}

A tarefa mais difícil em um filme dos Coen está em se apropriar do sentido daquilo que se vê. Os acontecimentos se desdobram por meio de razões sempre dúbias, em grande parte devido à impressão recorrente de que a narrativa não nos leva ao ponto para o qual deveria conduzir. Esses cineastas nos deixam uma sensação de dúvida, como se tivéssemos sido apresentados a um enigma que não se pode facilmente esclarecer. Não que seja propriamente difícil compreender as ações que ali se desdobram. Na verdade, são narrativas bastante claras, não problemáticas. Difícil é aceitar que todos os caminhos levem sempre a situações tão desconcertantes. Quando seus filmes se encerram, fica-se com uma sensação de absurdo, sentimento que os Coen encontraram um modo de transformar num riso nervoso.

Esse riso usualmente se relaciona com a morte, mas, contraditoriamente, o sentimento em si não é desagradável. Pois, aqui, tanto a violência quanto a destruição consistem em algo engraçado (MOTTRAM, 2000). Acompanhar a morte alheia não desperta uma sensação de repulsa. Difícil se torna apreender a razão exata pela qual os personagens encontram esse destino. É o desconforto de quem não consegue discernir os motivos de certos fatos. Os gestos não são claros, e percebemos apenas a recorrência de alguns traços que levam ao desastre. Marge é trivial; os sequestradores, cruéis; Jerry, covarde; e Wade Gustafson (Harve Presnell), avarento. Revelam-se tipos bem específicos, que colaboram, cada um à sua maneira, para a sensação de erro que esses filmes oferecem.

Um cinema baseado na terceiridade (DELEUZE, 1983, 1985; MARRATI, 2008; RODOWICK, 1997) se utilizou de uma relação de ideias. Para isso, certo tratamento em relação aos personagens foi sempre indispensável. Eles se transformavam em suportes para um conceito. Para os Coen, criaturas elaboradas a partir de certa tipologia introduzem uma incapacidade de a ação falar por si mesma. Seus gestos se ordenam segundo certos desígnios. 
E, nesse caso, as características atribuídas a tais seres vão numa direção fadada a encontrar a catástrofe. Já se tentou explicar esse fato recorrendo a uma suposta torpeza moral injetada em tais seres, motivada talvez por alguma perversidade de seus autores. Explicação fácil essa que trata tais criaturas como uma gente de quem não se poderia esperar nada melhor (MOTTRAM, 2000).

Se assim fosse, seus filmes se tornariam mais simples do que são. Pois, recorrendo à fraqueza de quem quer que seja, teríamos de acreditar que uma dada psicologia, seja dos personagens ou de seus autores, é essencial para o rumo tomado pela história. Seria possível supor que os acontecimentos se devem à personalidade daqueles que vemos - ou não agirem. Ocorre o contrário. Os Coen encontraram um meio de utilizar essa indecisão como um instrumento para deixar de lado as relações de causa e consequência que um cinema baseado na ação comportaria. Ao invés de acreditar na centralidade do binômio e do synsigno, esses diretores recuperam outra solução. Em seu trabalho, os personagens operam como formas, razão pela qual as tipologias se mostram sempre tão importantes.

Certo cinema encontrou uma alternativa para se descolar da ação, por um lado, assim como do registro documental da câmera, por outro. Os Coen seguem certos cineastas que se movimentavam em direção aos limites dessa arte. E, entre todos os diretores clássicos, nenhum se esforçou tanto quanto Hitchcock para elaborar uma solução a tal problema. Partindo tanto de uma aparente importância da ação quanto da pretensa identidade com o mundo, seu trajeto seguiu uma direção particular, da qual os Coen compartilham pontualmente a técnica. Para o diretor inglês, estava em jogo a apresentação de uma ideia, que éramos convidados a vislumbrar. Esse efeito decorre da reflexão sobre alguns temas pontuais: o desejo e o modo como retoma assuntos da morte e da meia-noite. Todo um arranjo precisava funcionar de modo ordenado para se obter esse resultado (DOUCHET, 1959a, 1959b, 1960; ROHMER; CHABROL, 1979; TRUFFAUT; HITCHCOCK, 2004).

Porém, o objeto que anima os Coen se distingue dos temas que capturaram Hitchcock. Os irmãos condenam seus personagens a um resultado constrangedor diante das expectativas criadas pela narrativa. Mas, se somos apresentados a gestos que observamos sem se depreender facilmente o significado, é porque eles perderam suas coordenações usuais. No cânone, soa recorrente que bandidos expliquem seus atos; que heróis tenham boas razões para salvar seus entes queridos; que criminosos tracem planos mirabolantes. Aqui, nos deparamos apenas com o último bandido e sua mudez; o pai-capitalista e sua sovinice; Jerry, mas também Carl, e sua parvoíce cega: nós os acompanhamos em gestos carentes das 
conexões que aprendemos a esperar graças a um conjunto de obras pregressas, que, agora, nos abandonaram.

Fargo se divide em dois momentos. 0 primeiro centra-se no plano absurdo de Jerry. A estupidez dos sequestradores faz tudo dar errado, mas parece difícil que alguém tenha acreditado em um resultado diferente. Em seu âmago, aquele crime tinha algo de esdrúxulo, convidando ao fracasso. Isso não é estranho à comédia de crime (LEITCH, 2002). Contudo, Fargo se distingue pelo modo como a ingenuidade do pedido de resgate passa à violência assassina, pois a morte de várias pessoas era perfeitamente evitável. 0 plano consistia numa vigarice sem sangue. Porém, um ato inesperado torna algo pouco crível em um pretexto para a destruição. Então, inicia-se a segunda parte do filme, um exemplar do cinema policial e da história de detetive. Começa uma investigação que, agora, acompanhamos não a partir da perspectiva do criminoso, mas do investigador.

Filme de indecisões, Fargo nunca parece certo do rumo que vai seguir, propenso a mudar de direção entre a investigação policial e as peripécias do vendedor de carros e de seus comparsas. Quebras de roteiro são uma característica dos Coen, e cumprem uma função precisa em sua obra. Seus filmes parecem sempre instáveis, propensos a oscilar entre vários caminhos. Alguém poderia enxergar aí a busca pela surpresa, mas não se trata disso. A instabilidade se revela um dos traços que torna essa obra tão própria. Se a dubiedade marca os Coen, é porque aquilo que observamos pode sempre nos enganar. Em seus filmes, não é estranho que, cedo ou tarde, o expectador se depare com alguma metamorfose da trama. Que Fargo se torne exatamente o oposto do que se sugere no início não parece estranho.

Se os Coen nunca se cansam de nos oferecer o contrário do que esperávamos, isso envolve os comentários sobre os gêneros dos quais esse cinema se apropria. Questão fundamental está na coordenação de certos elementos do cânone, em meio a releituras muito particulares dos problemas típicos ao romance noir e ao cinema policial. Nisso, os Coen tentam sempre inverter as coordenações de praxe. Numa solução desconcertante, tanto os inocentes quando os culpados são destruídos, sem distinção de mérito ou citação de justiça. Nega-se a chance de acreditar na salvação da vítima. Acompanha-se uma investigação que se resume à captura de um último culpado. Acima de tudo, vê-se uma detetive incapaz de solucionar o que quer que seja.

De fato, nada parece tão estranho quanto essa policial e seu inquérito inusitado. No gênero, o investigador conduz diligências que levam a conclusões incomuns. Isso se deve a seu brilho, que resguarda a salvação compulsória dos inocentes (THOMPSON, 2007). Mas o 
que ocorre em Fargo é mais trivial. Ao fim de um esforço de rotina na coleta de evidências, as conclusões de Marge não chegam a qualquer solução capaz de evitar o pior. Mas essa é apenas uma das metades de Fargo, e todo o filme é simétrico, com duas linhas paralelas correndo lado a lado. Enquanto a policial busca evidências através de seus hábitos de burocrata, Jerry tenta garantir junto ao sogro seu dote ao avesso. Contudo, a avareza de Wade dá uma direção inusitada ao plano. E, em outra surpresa desconcertante, presenciamos alguém que decide regatear o preço da própria filha.

Certo cinema de crime esteve associado a narrativas repletas de idas e vindas, cujo trajeto peripatético nos revelava um mundo de violência e corrupção. 0 noir substituiu a busca simples pelo bandido por uma complexa sucessão de eventos, um pretexto para se acompanhar um detetive vagando por um universo escuro. Mas, ao lado desse cinema noir, Borde e Chaumeton (1953) nos ensinaram que existiu o assim chamado documentário policial, cuja principal característica esteve em narrar certas aventuras a fim de nos ilustrar o heroísmo desse personagem. Fargo conhece bem essa distinção, situando-se entre a tentativa de examinar tanto as consequências dos planos de Jerry quanto a investigação de Marge. Mas o que o torna específico é o modo como aborda essa tendência, utilizando-se da comédia para explorar a ideia do erro. Essas duas metades de um mesmo engano convergem numa única direção, e é disso que Fargo se alimenta.

Cada uma das partes permite esse resultado, que remete ao fluxo de uma única ideia: uma visão que nos garante observar até onde o erro consegue chegar. E ele vai muito longe. A estupidez que guiou o sequestro conduz também à incapacidade de todos os envolvidos em providenciar uma solução viável ao caso. Embora essa trajetória pareça tão somente oscilar entre citações diversas a traços do gênero, não se trata de repetir certo conjunto de referências, mas de utilizá-lo para explorar um conceito. Fargo se revela exemplar devido a uma fórmula encontrada pelos irmãos. Ela consiste não numa viagem pelo passado do cinema. Remete à forma como duas dimensões distintas do cânone permitem a exploração de certa imagem-mental.

$\mathrm{Na}$ interpretação sobre os Coen, certas acusações parecem recorrentes. Alguns enxergaram nesses trabalhos uma reciclagem do cinema. Houve quem os considerasse como artistas pós-modernos (DUNNE, 2000; SEELEY, 2008), acusando-os algumas vezes de elaborarem um trabalho vazio, que apenas recuperaria o passado. Mas, em sua obra, são outras as finalidades dessas apropriações inusitadas. Ao contrário de tal pretensão pósmoderna, seu trabalho leva certas características estéticas ao ponto mais longínquo ao qual 
se pode chegar, desenvolvendo ao limite as propostas intrínsecas de certo estilo. Os Coen vão ao extremo do cinema convencional, sem nunca tocar aquilo que essa arte possui de mais radical.

Esse modernismo cinematográfico explora os limites da ação. Entre os artistas de sua geração, os Coen talvez sejam os cineastas da imagem-mental em sua expressão mais intensa. Em sua obra, esse é um traço não muito fácil de perceber. Tais diretores fizeram questão de se apresentar de modo despretensioso, como se fingissem que agem quase por acaso (LEVINE, 2000). Mas seus filmes ecoam uma consciência sobre o próprio cinema, refletindo sobre a representação e o papel desempenhado pela identificação entre a imagem e o expectador.

Conforme Fargo se desdobra, parece contar mais de uma história - e, novamente, isso não corresponde a nenhum demérito, mas a uma experiência das mais notáveis. Quando se inicia, o filme se assemelha à narrativa retirada daquele romance noir que descende de James M. Cain. Até um dado momento, mais parece uma narrativa sobre uma classe social envolvida em imbróglios por dinheiro, em busca por ganhos que desafiam a lei. Frágeis, pouco inteligentes e sem grandes habilidades frente às circunstâncias com as quais se deparam, são os casais criminosos de romances como O Destino Bate à Sua Porta (1934) ou Indenização em Dobro (1943), em planos em que nunca se cogita a chance de algo dar errado.

Nessa primeira parte de Fargo, sente-se que o foco vai se concentrar nestes criminosos pouco importantes e de perspicácia bastante limitada. Nada era mais improvável que esse sequestro. Talvez por isso, esse projeto não se distanciasse tanto daqueles planos que revelavam um tipo semelhante de violência assassina descuidada. Havia uma fragilidade na ideia de Frank Chambers em, junto de Cora, assassinar Nick Papadakis e, sem que ninguém percebesse, arrematar sua casa, seu posto de gasolina e seu restaurante barato. Ocorria o mesmo com Walter Huff e Phyllis Nirdlinger, cuja ideia parecia perfeita apenas na imaginação de seus executores.

A seu modo, cada um desses personagens se envolve em fantasias pessoais sobre sua esperteza somente para descobrir o quão falhos são. Mas, em Fargo, importa que tal enredo permita ao filme nos enganar, convencendo-nos de certa direção até que deixe de caminhar por ela. A obra nos dá a certeza do que não é somente no instante em que se torna outra coisa. Então, centra-se numa outra personagem e, consequentemente, também em outra trama. Quando Marge aparece, é ela que passa para o centro do enredo. E, concentrando-se nela, Fargo elabora outra variação desse gênero: variação sutil, mas repleta de sentido. Agora, 
o trabalho remete a outras expectativas, em que o homem da lei adquire uma dimensão inexistente nos romances de Cain.

\section{0 crime trocado e as muitas faces da imagem-mental}

A herança do romance noir se refere a uma forma literária, mas o problema ao qual Fargo se conecta remete a uma solução cinematográfica. Na especificidade da imagem em movimento, os Coen se assentam na herança legada por certos diretores, e não por escritores. Decerto, tais cineastas gostam de nos lembrar o quanto supostamente deveriam mais a determinados romances que ao próprio cinema (HINSON, 2006; LEVINE, 2000): são máscaras sobre máscaras, na invenção constante de outros personagens. Fargo depende menos de certas contingências romanescas. De modo próprio, a imagem-mental do crime típica aos Coen aponta para Hitchcock, na direção utilizada por esse diretor para introduzir o pensamento em seu cinema e, assim, chegar ao limite do cinema clássico.

Esse plano consiste em esvaziar a ação, deslocando-a, concedendo proeminência à certa ideia através da reflexão sobre uma forma, que, no caso de Hitchcock, envolve o crime trocado. Porém, ao invés de repetir essa proposta, os Coen concedem a ela uma dimensão particular, refletindo sobre esse legado. A esses diretores foi atribuída a maestria das citações, mas seu esforço ultrapassa o mero inventário de temas. Seu jogo de referências nunca é direto e a conexão se faz sempre de modo lateral. Mais que a repetição do "lixo branco" de Cain ou dos detetives de Raymond Chandler, os Coen invocam a forma cinematográfica contida na ideia de troca, visível através da investigação de Marge ou das barbaridades de Jerry.

Fargo é a narrativa sobre um marido que pretende transferir para outrem o sequestro de sua esposa. Que Jerry encomende um crime a alguns capangas elucida apenas parte desta lógica. Sem a sugestão de reciprocidade na relação entre esses personagens, estaríamos diante de um crime que o expectador acompanha, como num cinema baseado na ação, em que o público tem unicamente de se ater às nuances contidas no desenvolvimento de um plano para a descoberta e a captura desses bandidos. Esse filme tão somente narraria uma transação encomendada entre indivíduos. Assim, teríamos um espécime do cinema policial mais banal, sem as ironias que fazem esse filme ser aquilo que é.

0 conteúdo de Fargo é bem diferente. Jerry não apenas contrata dois criminosos recomendados por um ex-presidiário que consegue um serviço como mecânico na 
concessionária onde o marido desesperado por dinheiro trabalha. Há um evento no filme que muda tudo. É o ato estúpido dos sequestradores na estrada, que leva Jerry a receber um crime para si. Isso ocorre quando o que deveria ser um sequestro por procuração se torna algo maior: porque, após o assassinato na rodovia, o vendedor de automóveis se torna parte de outro acontecimento. Quando o vigilante rodoviário e as testemunhas no carro são mortos, a natureza do crime muda, e Jerry recebe parte daquilo que os seus comparsas contratados acabam executando.

Esse outro evento passa a dizer respeito não apenas a Carl e Gaear, mas também ao gerente de loja. 0 sequestro pertence à dupla, assim como o triplo homicídio se atrela a Jerry, como uma imagem clara e simétrica. É um circuito, que se completa quando cada personagem assume suas partes, no crime que se concede e naquele que se recebe. Embora se tenha comparado os Coen a tantos outros artistas, curiosamente, poucos se debruçaram sobre sua proximidade com certos traços essenciais a Hitchcock. 0 crime trocado havia sido a estratégia fundamental do diretor inglês para produzir suspense, transformando uma ideia em algo mais importante que a ação. Em Fargo, a imagem da troca conecta esses autores de modo notável.

Para o diretor inglês, os atos em si eram menos importantes do que as relações construídas através dessas ideias tão extremas, "roubar" ou "matar". Elas subordinavam as ações ao desdobramento de um pensamento que, de fora delas, as conectava. A terceiridade se distinguia da segundidade graças à ideia que coordenava partes distintas. Tema desenvolvido em tantos momentos, está em Disque M para Matar (Dial M for Murder no original, de 1954), em Pacto Sinistro (Strangers on a Train no original, de 1951), em Sombra de uma Dúvida (Shadow of a Doubt no original, de 1943), casos nos quais se vê o circuito que une instâncias diversas a partir de um terceiro elemento. A relação que passam a dispor devido às atribuições trocadas conectam diferentes gestos mediante a centralidade de um conceito (DELEUZE, 1983).

0 diretor inglês abriu um precedente que não parece estranho à obra dos Coen. Estas aproximações a Hitchcock invocam um problema de fundo: seu cinema nunca se mostrou muito disposto a apenas nos mostrar atos. É famosa a ojeriza do cineasta inglês aos "verossímeis", diretores que se preocupavam apenas em retratar na tela certas ações. Para isso, a intenção esteve sempre em explorar certas formas como meio de produzir efeitos sobre o público (TRUFFAUT; HITCHCOCK, 2004). Como Rohmer e Chabrol (1979) nos mostraram, Hitchcock consiste num criador dessas formas. Curiosamente, os Coen herdam 
essa mesma concepção, embora nunca a reivindiquem nem espelhem grande consciência sobre ela.

Para Hitchcock, importante era "preencher a tela com emoção", elaboração com que descrevia a experiência tão particular de envolver o público na narrativa. Ao contrário de acompanhar o desvelamento desse ou daquele mistério exposto pelo enredo, seus filmes serviam como mecanismos para explorar uma sensação - o suspense para o qual os eventos surgiam apenas como um álibi. 0 fundamento de sua técnica estava em compartilhar com 0 público segredos que os próprios personagens não conheciam, de modo a envolver a audiência na trama. 0 expectador dispunha de um lugar privilegiado, que Hitchcock explorava. Esse ponto de vista que o público desfruta graças a informações oferecidas pelo diretor permite antever algo que vai acontecer, e o resultado é uma sensação.

Mas isso é muito pouco. Essa técnica demanda que o filme se desenvolva estritamente segundo os pressupostos apresentados pela forma a qual obedece, e isso reduz o espaço para a verossimilhança. Ao contrário, lida-se com imagens que, apropriando-se de índices do real, ensaiam a liberdade de construir seu mundo próprio. As tramas precisam seguir sua ordem lógica, e certo uso dos personagens se mostra indispensável para se obter esse resultado. Graças aos traços que os guiam ao longo do filme, os personagens se revelam tipos. Em Os 39 Degraus (The 39 Steps no original, de 1935), o "Memory Man" morre de profissionalismo, pois ele sabe quais serão as consequências de revelar a informação demandada. Mas esse traço de sua personalidade precisa ser desenvolvido em toda a sua extensão para que a técnica de Hitchcock surta seu efeito.

Essa ideia permite às tramas se desdobrarem infinitamente, como a tapeçaria a qual Deleuze (1983) se refere. Esse filósofo argumentou sobre a menor importância de motivações metafísicas de Hitchcock. Mas parece difícil descartar o quanto essa coerência de propósitos, contida no desenvolvimento de certas expectativas, desenvolve-se segundo um conjunto estrito de sentimentos importantes para o diretor inglês: a angústia em relação ao sexo e o temor da morte. Esse suspense, a expectativa que permite preencher a tela com emoção, servia como um meio para introduzir tais assuntos, subordinando a eles a decisão narrativa. Os filmes de Hitchcock expunham problemas que ultrapassam o cotidiano, cuja forma poderia ser explorada ao tratar do crime. 
Submetido a essa ideia, o enredo consistia em um MacGuffin ${ }^{3}$ : um pretexto para permitir o abandono da verossimilhança, garantir a atenção a conceitos e admitir a submissão dos atos a certo tema a ele externo. Numa de suas tiradas mais hilárias, Hitchcock explica o MacGuffin: basta encará-lo como um objeto utilizado para capturar certos animais selvagens, embora isso se choque com a constatação de que tais criaturas não habitam o território sobre o qual se fala (TRUFFAUT; HITCHCOCK, 2004). Constata-se que esse estranho item possa se revelar qualquer coisa que aquele que o possui diz que ele porventura seja. Forma maleável, trata-se de um instrumento de pura ação. "Roubar" ou "matar" não significam nada: permitem roubar "alguma coisa" ou matar "alguém". Potências desse tipo elaboram a sequência de eventos que tornam o filme possível.

Isso ocorre em Intriga Internacional (North by Northwest no original, de 1959), quando a aventura peripatética se justifica de modo injustificável, e os motivos da perseguição ao inocente revelam o pretexto esdrúxulo da trama: os espiões estavam em busca de "planos do governo", motivo que se refere a qualquer coisa. 0 mesmo ocorre em Interlúdio (Notorious no original, de 1946), na intriga do urânio roubado que serve para explorar a ideia da culpa e do amor. Mas é o crime trocado que representa o indício mais efusivo desse resultado. Efeito radical, ocorre em filmes como Sob o Signo de Capricórnio (Under Capricorn no original, de 1949), no qual se trocam em perfeita simetria a culpa que o marido aceita por um crime cometido pela mulher e a pena que a esposa cumpre mediante o vício e a morte em vida. Apenas a revelação de seu segredo para um terceiro personagem pode reestabelecer a relação entre eles (ROHMER; CHABROL, 1979; TRUFFAUT; HITCHCOCK, 2004).

Porém, em nenhum filme essa ideia ficou tão clara quanto em Psicose (Psycho no original, de 1960). Sua construção envolve a troca mesclada a uma complexa racionalização sobre o desejo (DOUCHET, 1959a, 1959b, 1960). Aqui, não se trata apenas da reciprocidade de alguém injustiçado por um ato de outrem ou do crime intercambiado entre dois indivíduos. 0 mecanismo de Psicose já havia sido elaborado em Janela Indiscreta (Rear Window no original, de 1954), quando somos colocados diante não de uma investigação pautada por evidências concretas, mas da ilustração de uma vontade inconsciente. 0 crime do apartamento no pátio em frente se resolve menos devido a um conjunto qualquer de

\footnotetext{
3 MacGuffin consiste em um trocadilho utilizado recorrentemente por Hitchcock para designar sua técnica de exposição de uma história, de apropriação da atenção do público, de manutenção do suspense. Baseia-se na ideia de que a narrativa consiste num pretexto para as coordenações que pretende apresentar.
} 
deduções. Sua solução ocorre quando, inseridos no lugar do fotógrafo acidentado, assistimos, da perspectiva desse observador, algo que se desloca da concretude dos fatos para a elaboração de uma ideia.

Janela Indiscreta se estrutura em três dimensões: o cotidiano, a imaginação e o desejo. 0 primeiro elemento se refere ao que vemos quando observamos o apartamento do fotógrafo, onde tudo parece real, como se a relação com o mundo permanecesse intacta. 0 segundo ocorre durante o exame do prédio do outro lado do pátio, quando se acompanha aquilo que move a atenção do fotógrafo acidentado, confinado como o público desse espetáculo. Dessa posição, o personagem se torna o investigador de um crime. Mas isso depende não apenas da concretude do que ele - como nós - acompanhamos. Envolve também algo que o próprio personagem imagina, e que termina se tornando realidade como uma expressão subterrânea de seu desejo.

Pois o ato que Jeff (James Stewart) vê de sua janela representa a projeção de sua vontade de se ver livre de Lisa (Grace Kelly). Há aqui uma metáfora do próprio cinema, algo muito mais abstrato que um crime transferido de um homem a outro. Em outros filmes, o ponto de partida para o suspense esteve na posição especial de um expectador capaz de conhecer certos segredos ocultos para os personagens. Nesse caso, o movimento se mostra mais complexo. Quando a pretensa investigação projeta o expectador no interior do filme, estabelece-se o terceiro movimento, que envolve o pensamento. Os desejos ocultos da plateia sobre destruição e morte se tornam os objetivos que motivam os personagens. 0 mesmo ocorre em Psicose, só que, agora, o fotógrafo parece ter descido da tela para, conosco, observar o que ocorre com Marion (Janet Leigh).

$\mathrm{Na}$ conclusão de Douchet, aquilo que se inicia como um roubo realizado pela secretária são atos coordenados pelo desejo e capazes de materializar uma ideia. A primeira cena nos oferece a própria personagem, numa projeção que, presente em qualquer cinema, conecta o público às personas e aos atores. Mas seu efeito se consume posteriormente de modo bastante inusitado. Isso ocorre no ato de violência no chuveiro, quando a personagem se encontra nua como deveria ter estado no início do filme, indefesa contra um tipo de posse muito mais intenso que tudo que poderíamos supor na relação da moça com seu amante. Todo o desenvolvimento pregresso - o roubo e a fuga - transforma-se em gestos que concedem a possibilidade de desejarmos aquilo que nos é oferecido, mas o que se concede ao público é um ato muito mais perverso. 


\section{A paisagem abstrata do erro}

Para Hitchcock, essa ideia do desejo foi essencial. Mas outro tema se estabelece para os Coen. A imagem-mental empreendida pelos irmãos se concentra em elos construídos a partir do erro. Dele, os autores constroem outro formalismo, muito específico. Os personagens e as situações nas quais se veem envolvidos consistem em máscaras voltadas a permitir o desdobramento de um conceito. Sua exploração elabora um circuito, no qual os eventos se expandem graças a um conjunto de enganos, do qual o filme concede o vislumbre de seu percurso. O desdobramento da obra depende da expansão dessa ideia, que proporciona um movimento próprio ao conjunto. Esses vínculos passam de um ponto a outro, de um personagem a outro, de um ato a outro, de um instante a outro, abarcando todo o filme.

Quando os Coen soavam mais próximos a Hitchcock, surge a especificidade dos irmãos cineastas, e o traço aparentemente decisivo ao diretor inglês será apropriado de modo particular. Nessa quebra, o crime trocado em Fargo se revela presente, decerto. Mas sua operação envolve outra imagem-mental: a de um engano cujo resultado será a destruição de todos. Talvez fôssemos levados a pensar que Carl e Gaear seriam a própria imagem da imbecilidade, mas não é nada disso. A insistência com a qual surgem na tela personagens idiotas ou estúpidos não tem a feição agressiva que muitas vezes se atribuiu aos irmãos diretores.

Não há desprezo nos Coen; apenas a vontade de reinventar esse modelo anterior, transformando tudo em confusão. Os enganos são os mais diversos. Consistem na incapacidade de atarraxar placas falsas num veículo com no qual dois criminosos rodam por aí com a vítima no bagageiro. Há a incapacidade dos sequestradores em mensurar seus atos. Não existe lá muito controle por parte desses indivíduos sobre os rumos das decisões por eles tomadas. Foi dito que os Coen se esmeram em ilustrar que não existe plano capaz de resistir ao erro (MOTTRAM, 2000). Existe algo de disfuncional em seus personagens, mas a forma como os diretores lidam com essa ideia não se confunde com o desprezo.

Pensar assim significaria que, nesse cinema, os atos importam; que existiria alguma psicologia capaz de explicá-los. Mas tal obra versa com a tentativa de rever a troca. Quando os crimes distintos terminam se mesclando, isso ocorre de modo particular. Não é apenas um crime que se reparte em dois para supor que se possa solucionar essa distância por uma reconciliação. Essa resposta ocorreria através da confissão, como um gesto capaz de recuperar o que se rompeu. Para os Coen, tal solução parece pouco provável. Ao contrário da 
aposta conciliatória, os atos aqui se dispersam entre os personagens, como num exercício voltado a nos mostrar o quão longe uma catástrofe pode chegar.

Um mesmo desastre envolve vários personagens, dispersando-se de muitas formas. Se o plano atribuído por Jerry à dupla se volta contra seu criador, isso se dá devido ao erro acionado por Carl e Gaear. Essa dispersão não conhece limites, e a chave de Fargo está no modo como tal efeito não apenas atinge os vilões. Ele também aniquila Jean, a vítima que se espera salvar, mas cujo fim os Coen nem ao menos se dignam a nos mostrar. Essas imagens poderiam nos conceder uma chance de crer em sua salvação. No último instante, alguém viria em socorro da pobre mulher, como ocorre no cinema que se baseia no conflito entre dois.

Mas essa morte ocorre fora de quadro, e dela somos informados no diálogo antes da desavença final entre os sequestradores. Uma vítima pressupõe a esperança de salvamento. Na imagem-ação, essa solução aconteceria através da montagem concorrente/convergente, no binômio que remete a um duelo capaz de se encerrar com a salvação da moça. 0 objetivo dos Coen é outro. Para se manter fiel ao desdobramento imposto pela ideia que guia essa obra, Jean será um personagem insignificante, desses que se vê apenas uma única vez. É a cena absurda do sequestro, após a qual a vítima desaparece. Escutaremos sua voz na mala do carro, e é tudo.

Certos filmes flertaram com certa inversão desse duelo, mas a decisão dos Coen envolve menos a tentativa de subverter os ritos do confronto. Alguns diretores, como o Brian De Palma de Um Tiro na Noite (Blow Out no original, de 1981), buscaram abandonar a exigência por uma conclusão feliz, negando ao público aquilo que ele tanto esperava. Ao contrário dessa reversão, inserida ainda na imagem-ação, lida-se aqui com um cinema de outro tipo. Assim, nada mais natural que a contraposição de duas metades seja abandonada em prol de outra relação. Pois não é matar ou roubar que se encontra em jogo na ideia que os Coen coordenam, mas outra estruturação.

0 momento em que o erro atinge dimensão maior se refere ao destino das vítimas. Pois o maior engano de Fargo está na incapacidade de Marge em chegar ao local do crime antes que deixe de existir qualquer inocente para salvar. Tudo se torna uma questão de tempo: caso tivesse descoberto o enigma que os detetives do cânone foram elaborados para desvendar, Jean ainda poderia ser resgatada com vida, e a morte de Wade no estacionamento teria sido evitada. Mas essa detetive se guia menos pela sagacidade - que equivale quase a um dom premonitório que abençoa heróis desse tipo - e mais pelo caráter caseiro de seus procedimentos pouco apropriados a esse acontecimento brutal. 
Para elaborar suas conexões, Marge não conhece outro procedimento além de suas perguntas de rotina. Elas levam a policial até o motel onde o carro utilizado pelos criminosos no sequestro foi visto pela última vez. Esse elo permite o rastreamento das ligações feitas de um telefone público próximo do local. Um dos números discados havia sido o da concessionária; o outro, o de Shep Proudfoot (Steve Reevis). Tais telefonemas levam Marge até Jerry, e - imagina-se - esse deveria ser o instante em que uma epifania a faria identificar o culpado. Todavia, quando ambos se encontram, não existe qualquer suspeita em relação ao vendedor. Marge conduz seu encontro com o culpado sem a iluminação relativa a seu envolvimento - o que, aliás, ela jamais vai descobrir por si mesma.

Até o arremedo de supercérebro do crime se revelar incapaz de controlar suas emoções, nenhuma suspeita de Marge recai sobre Jerry. Talvez nenhum interrogatório cinematográfico tenha se distanciado tanto daquilo que define os detetives do cânone. A conversa não leva a lugar algum. A policial parece incapaz de perceber os atos suspeitos, gesto importante devido ao fato de, no cânone, eles serem sempre invisíveis para outros olhos à exceção do detetive. É necessário que o vendedor de automóveis praticamente assine uma confissão, fugindo do interrogatório que mais parece uma conversa trivial. Na estrada, Marge havia até mesmo parecido esperta. Contudo, naquela situação, era o caso apenas de seguir caminhos já traçados. 0 encontro com Jerry demanda uma sua sagacidade que ela nunca vai demonstrar.

A visão que escapa a Marge evitaria todas as mortes. Porém, para a policial, as evidências parecem sempre impossíveis de concatenar com a perspicácia necessária. Não significa que ela seja idiota. Afinal, a detetive entende o que significa o registro no caderno do patrulheiro rodoviário. As letras DLR não se referem ao início de uma tentativa de anotar qualquer placa, como pensou Gary (Cliff Rakerd). São uma identificação de concessionária. Marge percebe algumas conexões, mas outras - as mais importantes - não. Ela nunca alcança aquilo que os detetives enxergam. Falta-lhe inteligência? Não: a personagem carece da dádiva imponderável que procedimento algum substitui.

Seria impossível imaginar Dirty Harry (Clint Eastwood) ou Bullitt (Steve McQueen) numa conversa como a de Jerry e Marge. Pode-se ir ainda mais longe, ao supor que o essencial do diálogo escaparia a um Philip Marlowe ou um Continental Op. Esses exemplos clássicos do ofício de investigador tinham o dom de adivinhar o que ia ocorrer sem qualquer evidência concreta. Há algo de malicioso no olhar desses personagens, uma capacidade de enxergar algo fora do alcance daqueles que se acomodaram com a cotidianidade do mundo 
(THOMPSON, 2007). A tarefa dessas criaturas é nos revelar o que se encontra além das conexões triviais do dia-a-dia. Isso, Marge nunca alcança. Pois sua natureza é o oposto. Que os Coen tenham escolhido a mais improvável dos detetives, uma mulher grávida, apenas reforça essa ideia da vida suburbana.

Nessa investigação incompleta, a solução do crime - ou, na verdade, a reles prisão do último criminoso - deve-se àquilo que falta à detetive, e não ao que precisaria ter. Se Fargo se tornou uma narrativa policial, foi tão somente para inverter as prerrogativas do gênero, produzindo a máscara de um engodo. Ao contrário do que se espera desse tipo de enredo, a solução do caso, embora se reverta na prisão de seus responsáveis, carece do irremediável senso de satisfação que esse acontecimento carregaria consigo. A conclusão se deve novamente a um engano. 0 gesto que conduz ao culpado envolve tão somente a inabilidade do perseguido. Fosse Carl um pouco menos linguarudo, Marge jamais chegaria até o Ciera.

É a falastrice do bandido que desperta suspeitas. Novamente, são grupos de erros em sequência que concedem a qualquer plano o efeito oposto ao que dele se esperava. As ameaças vociferadas pelo sequestrador num balcão de bar terminam chamando a atenção de um homem qualquer, para quem o bandido, de outro modo, passaria despercebido. Suas bravatas e ameaças falam sobre morte no momento menos apropriado. Afinal, esse não é um assunto adequado quando a notícia de um homicídio triplo ronda uma comunidade pequenoburguesa de Minnesota. Em um lugar repleto de gente tão ordeira quanto parva, qualquer um deduziria o quanto isso despertaria suspeitas.

Mas essa visão se encontra além da mecânica de Carl. Ele também termina por obedecer a seus próprios modelos, como fazem todos em Fargo. Seu destino não poderia ser diferente daquele que aguarda os demais. Um depoimento qualquer, colhido pelo trabalho trivial de Gary, leva ao Lago Moose, e daí a Gaear. Acontecimentos desconexos capazes de revelar conexões decisivas não são absolutamente estranhos ao filme de crime. Exatamente o contrário: esses elos absurdos são necessários para que se solucione uma intriga que ultrapassa a fria coordenação de evidências. Mas o desfecho de Fargo se deve tanto à dificuldade de Marge em desvelar a identidade de Jerry quanto à de Carl em esconder-se. 


\section{Considerações finais}

Os equívocos de um plano tão improvável levam também à incapacidade dos envolvidos em providenciar-lhe uma solução. Essa dificuldade conduz à morte de quase todos, e a policial entra em cena apenas para garantir a detenção do último envolvido. Ao ser preso, Gaear surge como o único culpado ainda vivo. A sobrevivência costuma ser uma benção concedida aos inocentes, que atravessam um universo maligno repleto que criaturas cruéis, no qual apenas um único indivíduo se mostra capaz de se manter de pé (CLOVER, 2015). Em Fargo, deparamo-nos não com um derradeiro inocente, mas com um culpado final, numa inversão brutal dessas expectativas cinematográficas. Os personagens que tombam ilustram a ausência de catarse do filme, pois esse envolvimento emocional passa longe dos Coen.

Esvaziando os gestos, há apenas máscaras às quais todos os personagens estão presos, revelando o caráter periférico das ações que deveriam guiá-los. Essas criaturas se mostram estáticas. Tem-se a sensação de que não evoluem, repetindo sempre os traços que as definem. Conforme os fatos se desdobram, os eventos apenas revelam sua pouca importância, pois nada desmobiliza a catástrofe desde o início pressentida. Há apenas uma ideia, e importa desdobrá-la segundo suas exigências intelectuais. Em Fargo, Jerry espelha a inconsequência ingênua e cega; Wade é um negociante avarento capaz de barganhar pela vida da filha; Gaear ilustra a agressividade e a violência sem qualquer controle; Carl se orienta pela compulsão ao confronto verbal.

São comportamentos claros como um mecanismo. Desde que se aceite seu caráter, as ações são de uma rigidez matemática. Seus efeitos articulam partes dissociadas como muitas frações, permitindo-nos observar seus efeitos. A composição do filme nos leva a certo desfecho devido a engenhocas compostas por muitas engrenagens. Importa pouco o pretenso significado do enredo, a plausibilidade de certas cenas ou de certos personagens. Interessa o impacto produzido. 0 erro procede como uma encenação que guia o funcionamento dessa geringonça. A coordenação de imagens torna visível esse conceito, e as relações entre os envolvidos dependem de tal engenharia, sendo a narrativa um gigantesco engodo, um MacGuffin muito particular. 


\section{Referências}

ADAMS, Jeffrey. The Cinema of the Coen Brothers: Hard-Boiled Entertainments. Nova York: Wallflower Press Book, 2015.

BORDE, Raymond; CHAUMETON, Etienne. A Panorama of American Film Noir 1941-1953. San Francisco: City Lights Books, 1953.

CIMENT, Michel; NIOGRET, Hubert. Interview with Joel and Ethan Coen. In: ALLEN, WILLIAM RODNEY (Org.). The Coen Brothers: Interviews. Minneapolis: University of Minnesota Press, 2006. p. 25.

CLOVER, Carol J. Men, Women, and Chain Saws: Gender in the Modern Horror Film. Princeton: Princeton University Press, 2015.

COEN, Ethan. Introdução. In: COEN, ETHAN; COEN, JOEL. Fargo. Rio de Janeiro: Rocco, 1997. p. 5-9.

DELEUZE, Gilles. A Imagem-Movimento. São Paulo: Brasiliense, 1983.

DELEUZE, Gilles. A Imagem-Tempo. São Paulo: Brasiliense, 1985.

DOUCHET, Jean. Hitch et son public. Cahiers du Cinéma, Paris, v. 113, p. 7-15, nov. 1960.

DOUCHET, Jean. La Troisième clé Hitchcock. Cahiers du Cinéma, Paris, v. 99, p. 44-55, set. 1959a

DOUCHET, Jean. La Troisième clé Hitchcock (II). Cahiers du Cinéma, Paris, v. 102, p. 17-29, dez. 1959b.

DUNNE, Michael. Barton Fink': intertextuality, and the (almost) unbearable richness of viewing. Literature-Film Quarterly, Nova York, v. 28, n. 4, p. 303-311, out. 2000.

FARGO. Direção de Joel Cohen e Ethan Coen. Produção de PolyGram Filmed Entertainment, Working Title Films. Seattle: Amazon Prime, 1996. (96 min), color.

HINSON, Hal. Bloodlines. In: ALLEN, WILLIAM RODNEY (Org.). The Coen Brothers: Interviews. Minneapolis: University of Minnesota Press, 2006. p. 3-16.

LEITCH, Thomas. Crime Films. Cambridge: Cambridge University Press, 2002.

LEVINE, Josh. The Coen Brothers: The Story of Two American Filmmakers. Toronto: ECW Press, 2000.

LEWIS, Jon. The Coen Brothers. In: TASKER, Yvonne (Org.). Fifty Contemporary Film Directors. Nova York: Routledge, 2011. p. 116-126. 
MARRATI, Paola. Gilles Deleuze: Cinema and Philosophy. Baltimore: Jonhs Hopkins University Press, 2008.

MOTTRAM, James. The Coen Brothers: The Life of the Mind. Dulles, VA: Brassey's, Inc, 2000.

PALMER, R. Barton. Joel and Ethan Coen. Champaign: University of Illinois Press, 2004.

RODOWICK, David Norman. Gilles Deleuze's Time Machine. Durham: Duke University Press, 1997.

ROHMER, Eric; CHABROL, Claude. Hitchcock, the First Forty-Four Films. Nova York: Ungar Film Library, 1979.

SEELEY, Tracy. O Brother, What Art Thou? Postmodern pranksterism, or parody with a purpose?. Post Script, Nova York, v. 27, n. 2, p. 97, 2008.

THOMPSON, George. Hammett's Moral Vision. San Francisco: Vince Emery Productions, 2007.

TRUFFAUT, François; HITCHCOCK, Alfred. Hitchcock/Truffaut: Entrevistas. São Paulo: Companhia das Letras, 2004.

\title{
An abstract landscape: Fargo, the error and the mental-image
}

\begin{abstract}
Fargo, a film by Joel and Ethan Coen, will be analyzed aiming to interpret it towards Deleuze's concept of mental-image. Despite his apparent format of conventional crime comedy, this opus consists of an example of a work localized at the edge of classical cinema, never breaking with its limits. The film is understood as an indication of a detachment from the action-image, recurring less to the synsign/binomial, resource intrinsic to the secondness. In Fargo, the contraposition between the acts and the events which will guide then from a situation to another becomes dispensable. Submitting the gestures to an idea, it becomes possible to the movie to operate according to a thirdness, introducing thinking in the image and conferring centrality to a concept defined by the error, which the work happens to be his illustration. Fargo exploits this mechanic, in gestures condemned to conduct to the destruction of everything that constitutes his plot.
\end{abstract}

\section{Keywords}

Mental-image; Coen Brothers; Deleuze 


\section{Autoria para correspondência}

João Martins Ladeira

joaomartinsladeira@gmail.com

\section{Como citar}

LADEIRA, João Martins. Uma paisagem abstrata: Fargo, o erro e a imagem-mental. Intexto, Porto Alegre, n. 52, e-99882, jan./dez. 2021. DOI: http://dx.doi.org/10.19132/1807-8583202152.99882

Recebido em 27/01/2020

Aceito em 06/08/2021 